\title{
Potential and Actual Cognitive-Emotional Engagement with Characters: A Response to Michael Whitenton and Bonnie Howe \& Eve Sweetser
}

\author{
Ralf Schneider \\ Institute of English, American and Romance Studies \& Aachen Center for \\ Cognitive and Empirical Literary Studies, RWTH Aachen University, Aachen, \\ Germany \\ ralf.schneider@ifaar.rwth-aachen.de
}

\begin{abstract}
This article addresses the contributions by Michael Whitenton, and Bonnie Howe and Eve Sweetser, in the present volume. I endorse all three contributors' use of cognitivelinguistic approaches, highlighting their helpfulness for the reconstruction of frames that shape the reading experience of audiences located in different historical and cultural contexts. The two chapters meticulously trace the complexity and dynamics of understanding exemplary biblical characters. I emphasise that the level of attention to linguistic detail displayed by cognitive stylistics is a desideratum for a readeroriented analysis of a text's potential reading effects. At the same time, I question some assumptions in cognitive linguistics concerning the cognitive-emotional processes real readers are actually likely to perform. The two chapters serve as a starting point for me to discuss general tendencies in recent cognitive and empirical literary studies, which have perhaps overstated the intensity and impact of some processes, while overlooking others that may be just as important.
\end{abstract}

\section{Keywords}

cognitive linguistics - character analysis - mental character model - cognitive and empirical literary studies - actual readers 


\section{Introduction}

Biblical characters are of interest to scholars of modern literature for at least two reasons. First, modern literature is full of references to motifs, passages, and characters from the Bible. Well into the twentieth century, authors could rely on their readers to recognize the scriptural implications when, for instance, a character was named after a figure from the Old or New Testament, which would result in an enriched characterisation. Second, there is a tension between biblical characters and characters in modern prose narrative. In one sense, biblical characters are like other fictional beings. As Uri Margolin sums up, literary characters in general are storyworld participants, they are introduced through linguistic means (names, descriptions, and pronouns), they are constructed by writers "for some purpose", they are "non-actual but wellspecified individual[s] presumed to exist in some hypothetical, fictional domain", and they are "text-based construct[s] or mental image[s] in the reader's mind". ${ }^{1}$ All of this also pertains to characters in the Bible, so that they would seem to invite the same cognitive and emotional responses in readers as do their modern counterparts. In a significant sense, however, the figures in the gospels are quite different from characters in modern prose fiction, at least from the reader's perspective: a whole set of factors outside the text affects the way we read, and the cognitive control systems we consciously or unconsciously apply to the reading of a text ${ }^{2}$ can lead to substantially different reading processes. These factors are partly dispositional and habitual, partly situational, and they emerge from a combination of reader variables with text features. Reading expectations and the readiness to engage with characters in fictional worlds will already be influenced by the selection of reading material. ${ }^{3}$ Cognitive-emotional engagement will differ whether we confront ourselves with, say, a crime novel, a realist novel, a modernist or post-modern narrative, or a parable in Scripture. Furthermore, in naturally occurring reading situations (i.e. outside the test setup and the laboratory) the different kinds of situatedness of leisured reading of prose fiction at home, reading and

1 U. Margolin, "Character," in D. Herman (ed.), The Cambridge Companion to Narrative (Cambridge: Cambridge University Press, 2007), pp. 66-79 (66).

2 W. Kintsch, "The Role of Knowledge in Discourse Comprehension: A Construction-Integration Model," Psychological Review 95 (1988), pp. 163-182; R.A. Zwaan, "Effect of Genre Expectations on Text Comprehension," Journal of Experimental Psychology: Learning Memory and Cognition 20 (1994), pp. 920-933.

3 R.A. Mar, K. Oatley, M. Djikic, and J. Mullin, "Emotion, and Narrative Fiction: Interactive Influences Before, During, and After Reading," Cognition and Emotion 25 (2011), pp. 818-833 $(819-822)$. 
discussing texts in a Bible reading group, or listening to a pericope in a church service, will prime a number of attitudes and expectations as to how the texts in question can or need to be understood. This tension between the biblical characters and those in modern prose fiction makes them particularly interesting for current reception-oriented literary scholarship, since it throws the characteristics of both into relief. In particular, it raises the question what common ground there is between the authors of the gospels and today's readers. The two papers by Michael Whitenton, and Susan Howe and Eve Sweetser employ concepts from cognitive scholarship - mental spaces, conceptual blending, embodied cognition, frames, and viewpoint - that have also been used in the study of modern, or contemporary fiction to do precisely that. Both articles demonstrate the usefulness of such approaches, and at the same time they also point to some open questions and challenges the reader-oriented study of narrative is confronted with.

\section{Self-Positioning: Cognitive and Empirical Literary Studies}

My perspective is that of Cognitive and Empirical Literary Studies, the roots of which lie in reader response theory, or reception theory. As is well known, these approaches placed greater emphasis on reader's interaction in the production of meaning than the more text-focused traditions of both structuralist and post-structuralist literary criticism had done. Works by Louise Rosenblatt, Stanley Fish, Norman Holland, and particularly Wolfgang Iser inquired into the dynamic processes of meaning-construction in reading. ${ }^{4}$ But while Iser based his conceptualisation of the act of reading on Edmund Husserl's and Roman Ingarden's phenomenological theories, ${ }^{5}$ scholars in cognitive psychology and psycholinguistics at the same time developed theories and models for the study of text understanding, or discourse processing. ${ }^{6}$ That discipline also

4 See, e.g., T. Eagleton, Literary Theory: An Introduction, 3rd edn (Minneapolis: University of Minnesota Press, 2nd edn, 2008), pp. 47-78.

5 W. Iser, The Implied Reader (Baltimore: Johns Hopkins University Press, 1974) [orig.: Der implizite Leser: Kommunikationsformen des Romans von Bunyan bis Beckett (Munich: Fink, 1972)]; W. Iser, The Act of Reading: A Theory of Aesthetic Response (Baltmimore: Johns Hopkins University Press, 1987) [orig.: Der Akt des Lesens: Theorie ästhetischer Wirkung (Munich: Fink, 1976)].

6 W. Kintsch and T.A. van Dijk, "Toward a Model of Text Comprehension and Production," Psychological Review 85 (1978), pp. 363-395; Kintsch, "Knowledge" R.A. Zwaan, Aspects of Literary Comprehension (Amsterdam: Benjamins, 1993); B.K. Britton and A. C. Graesser (eds.), Models of Understanding Text (Mahwah: Erlbaum, 1996). 
promised to offer reception theory more fine-grained process models of the mental operations involved in reading. The notion of 'gap filling,' for instance, that is central to phenomenological reception aesthetics (Rezeptionsästhetik) but rather vague - basically any information not spelled out by the text may be a gap that the reader can fill - found its cognitive-psychological counterpart, e.g. in the study of inferencing. ${ }^{7}$ The CL work on frames that provide entire knowledge structures that can be triggered by references to any of their component elements provides another firm grounding for the explanation of how Iser's elusive Leerstellen are actually filled. Based in the experimental tradition of psychological research, the discourse processing approaches opened the investigation of literary understanding to empirical testing. ${ }^{8}$ It appeared that the predominance of reader constructs used in reader-oriented literary scholarship $^{9}$ might be replaced by well operationalised cognitive-psychological process models of text understanding and hypotheses that could actually be tested with real readers as subjects.

Around the late 199os cognitive science was beginning to grow into the broad and multidisciplinary field that it now is. The development of cognitive and empirical studies of literature is by no means concluded, but keeps receiving input from such diverse disciplines and sub-disciplines as cognitive narratology, film studies, media psychology and (mass) communication studies, general cognitive psychology, cognitive linguistics and semiotics, philosophy of mind, cognitive poetics and cognitive stylistics. All of these approaches have contributed to our understanding of the production and particularly the reception of literature, and literature keeps being of interest to the cognitive sciences as an example of the stunning complexities and dynamics of the processes of the human mind. Michael Burke and Emily Troscianko aptly speak of a Cognitive Literary Science. ${ }^{10}$

7 Cognitive-psychological concern with dynamic mental operations lay bare the sheer complexity of the processes, so that it is no surprise that scholars came up with competing models. For different conceptualisations of inferencing see G. McKoon and R. Ratcliff, "Inference During Reading," Psychological Review 99 (1992), pp. 440-466 and A.C. Graesser, M. Singer, andT. Trabasso. "Constructing Inferences during Narrative Text Comprehension," Psychological Review 101 (1994), pp. 371-395, respectively; for a discussion and an alternative view that focuses on normal memory processes, cf. R.J. Gerrig and E. O'Brien, "The Scope of Memory-Based Processing," Discourse Processes 39 (2005), pp. 225-242.

8 A foundational work on the empirical study of response to narrative is M. Bortolussi and P. Dixon, Psychonarratology: Foundations for the Empirical Study of Literary Response (Cambridge: Cambridge University Press, 2003).

9 R. Schneider, "Reader Constructs," in D. Herman, M. Jahn, and M.-L. Ryan (eds.), The Routledge Encyclopedia of Narrative Theory (London and New York: Routledge, 2005), pp. 482-483.

10 M. Burke and E.T. Troscianko (eds.), Cognitive Literary Sicence: Dialogues between Literature and Cognition (Oxford: Oxford University Press, 2017). 
Within this field, my interest has been in the processes and effects of readers' reactions to characters in narrative. ${ }^{11}$ While my first contributions to the field were strongly influenced by discourse processing research, I am currently trying to tie input from the various strands that have developed since then together into an integrative approach, both theoretically and methodologically. ${ }^{12}$ A comment on the denomination of the field is in order, because the conjunction in Cognitive and Empirical Literary Studies is not necessarily clear: Empirical testing of hypotheses concerning reader's responses to literary text ought to be grounded in cognitive-psychological models of understanding, observe the rules of the experimental sciences, and aim at statistical validity. ${ }^{13}$ However, Cognitive Literary Studies can of course also proceed without empirical testing ${ }^{14}$ and, obviously, has to in the case of historical readers and readings. Although the use of scientific methods of empirical testing for the corroboration of response hypotheses has turned into a fruitful branch of research, not all phenomena of interest to cognitive narratologists or cognitive linguists are easily testable, at least not with the methods currently available and in use. Strict experimental design precludes testing hypotheses concerning very complex mental operations (such as the activation of frames, or blending), while studies involving questionnaires and various types of interviews tend to capture the phenomenological level of the reading experience. These experiences are accessible to conscious introspection, or retrospection, but there is a large number of processes that occur automatically and unconsciously in every reading and that we simply cannot call back to our conscious

11 R. Schneider, Grundriß zur kognitiven Theorie der Figurenrezeption am Beispiel des viktorianischen Romans (Tübingen: Stauffenburg, 2000); R. Schneider, "Toward a Cognitive Theory of Literary Character: The Dynamics of Mental-Model Construction," Style 35 (2001), pp. 6o7-640; R. Schneider, "The Cognitive Theory of Character Reception: An Updated Proposal," Anglistik 24 (2012), pp. 117-134; J. Eder, F. Jannidis, and R. Schneider (eds.), Characters in Fictional Worlds: Understanding Imaginary Beings in Literature, Film, and Other Media (Berlin and New York: De Gruyter, 2010).

12 R. Schneider, "Cognitive-Emotional Response Scenarios: An Integrative Framework for the Study of Engagement with Narrative" (in preparation).

13 W. van Peer, F. Hakemulder, and S. Zyngier, Scientific Methods for the Humanities (Amsterdam: John Benjamins, 2012); J. Alber, C. Kutsch, and S. Strasen, "Empirical Methods in Literary Studies," in A. Nünning and V. Nünning (eds.), Methods of Analysis in Literary Studies (Trier: WVT, 2021), pp. 273-296.

14 For ways of making use of Cognitive Literary Studies non-empirically, see R. Schneider and D. de Muijnck, "Methods of Reception Theory and Cognitive Approaches - From Reception Aesthetics to Cognitive Poetics," A. Nünning and V. Nünning (eds.), Methods of Analysis in Literary Studies (Trier: WVT, 2021), pp. 251-272. 
minds. ${ }^{15}$ To access these unconscious processes, one would have to either use physiological measures (e.g., heart rate, skin conductivity) or behavioural ones (such as tracking the eye movements of readers) or to develop indirect tests that allow one to draw inferences on the non-conscious activities of the mind (e.g., memory tests). Even without actually being able to empirically corroborate all hypotheses concerning potential reading effects with actual readers, the minimum requirement for a cognitivist approach to reader response is an explication of the mental processes supposed to underpin the understanding of a text, and an awareness of the factors responsible for individual differences in readers. Since purely situational factors are practically impossible to hypothesise, we must be particularly careful to spell out which knowledge structures and mental dispositions are likely to be at work in the reading of particular texts. The two articles under consideration here contribute to this kind of endeavour.

Response to Michael Whitenton and Bonnie Howe \& Eve Sweetser

\subsection{Appreciation}

Both chapters deal with fairly complex mental operations likely to be involved in readers' construction of the meaning of passages from the Gospel according to John and Luke, respectively. Both demonstrate how models of mental operations and a precise look at the linguistic qualities of the texts combine to arrive at plausible hypotheses of reader response. Michael Whitenton showcases the usefulness of a blending-based approach to character in the gospels in two ways. First, to conceive of the mental modelling of a biblical character in terms of the integration of input spaces allows one to disentangle both the astounding complexities and the dynamics of character reception that account for central reading effects. The former issue concerns the potential intra-textual and extratextual input spaces that can be activated to make sense of a character, as Whitenton shows in figures 3 and 4 , for characters and their reappearances in general, and in figures 5 through 7 for the early version and the subsequent mental models that readers are likely to construct of Nicodemus. The latter point becomes apparent extremely well in the analysis of the versions of 'Nicodemus' that readers or listeners encounter in

15 R. Gerrig, "Conscious and Unconscious Processes in Readers' Narrative Experiences," in G. Olsen (ed.), Current Trends in Narratology (Berlin and Boston: De Gruyter, 2011), pp. 37-6o; B. Vermeule, "The New Unconscious: A Literary Guided Tour," in L. Zunshine (ed.), The Oxford Handbook of Cognitive Literary Studies (Oxford: Oxford University Press, 2015), pp. 463-482. 
John 3-4, 7, and 19. Updating the mental character model of Nicodemus, recipients must be able to conceptually integrate the different appearances, and, as Whitenton demonstrates, the final state is one with a considerable effect. The change of Nicodemus' allegiance, resulting from another blend (as a change in love), requires what I have called a 'de-categorization.'16 My own former approach to the dynamics of character reception was developed without taking recourse to blending theory. Within the earlier framework, the analysis would have stopped at saying that readers will have to discard their previous categorisations of Nicodemus to arrive at a fresh model of that character at the end. This will create at least a moment in which the character model needs to be reconfigured and kept 'open' for new information. Such de-categorisation is likely to attract the readers' conscious attention, a likelihood that the conversion narrative - probably like many others in the Bible - makes use of to drive the point home. Reconceptualising the formation of mental character models from the perspective of blending theory adds a new quality to the descriptive power of the theory. Beyond mere de-categorisation, the change in Nicodemus can now be seen as even more powerful: fully integrating all they know about Nicodemus, readers will not only re-form their mental model, but with the previous input spaces remaining accessible, backward projection will highlight the differences. This amounts to saying that where Nicodemus eventually ends up as a character is informed by an awareness of where he came from, and that the dynamics of his change - which can very plausibly be linked with the completion and elaboration phases of the blending process - is part of the emergent meaning of the final blend. Withenton's combination of a mental-model approach with blending theory advances the reception-oriented theory of literary character considerably.

Second, a blending approach can explain how different readings of a passage may come into existence. Whitenton carefully reconstructs frames, both literary ones, such as Plato's Symposium or the dissembler figure, and realworld frames, such as the funeral that the original audience were very likely to activate. Such a reconstruction can serve as a starting point for considering different readers' mental construals of the same text in other historical and socio-cultural contexts, in which other input spaces than the Symposium would probably be more readily available. Bonnie Howe and Eve Sweetser, who turn to the question of common ground, also make use of the concept of semantic frames. They demonstrate that the availability of knowledge structures guiding the reading will differ between the first-century readers (or listeners) of Luke and the twenty-first century audience. The reconstruction of

16 Schneider, “Cognitive Theory," pp, 20o1: 619-624; Schneider, “Updated Proposal," pp. 124-127. 
potential historical reception situations requires extensive reading in cultural history. This is not only necessary to reconstruct the conceptual knowledge readers share in different societies. Howe and Sweetser also show that embodied knowledge is far from being a-historical, and that cultural frames shape conceptualisations of the body: the example of "the gut as the locus of emotional response and empathic energy (not the heart, as in modern framing)" (p. 485) points to the differences between a first century response to the parable of the Compassionate Samaritan on a very basic, embodied level.

Another important point Howe and Sweetser make is that frames enable understanding even across spatio-temporal distances between producers and receivers of texts. While this is true of literary communication in general, the historical and cultural distance between the Bible and its readers of today is vast. The cognitive-linguistic concept of Ground helps explain why understanding is still possible in spite of this distance. The lowest common denominator between producers and recipients of texts are basic human activities and experiences - "talking, walking, pouring oil, lifting a heavy load, thirst and pain," "hospitality and travel customs," and "the human ability to feel for characters" (p. 470) in the Compassionate Samaritan - which account for the knowledge shared by Luke's narrator and the readers across time and space. It is an implication of the notion of Ground that the farther the distance (in cultural, spatial and temporal terms) is between the producer and the recipient of a text, the less culturally specific and the more basic is the knowledge that both 'share.'

The genre of the parable, as Howe and Sweetser point out, employs flat, two-dimensional characters: "Parables operate with stock characters and conventional actions; that is how they become so portable, so widely projected and applied" (p. 483). Stock characters are likely to be processed by virtue of what I have called a categorised mental character model, ${ }^{17}$ i.e., readers will consider the function of such characters to be clear early on in the narrative and save their processing capacities to focus on other aspects of the storyworld. These other aspects include in particular those characters that do not fit any category or whose category membership is not sufficient to explain their actions and create a coherent impression of the character. Such characters are frequently cast in immediate contrast to the flat, categorised characters, and they tend to receive more narratorial attention. The figure of the Compassionate Samaritan appears to be a case in point - "The Samaritan, by contrast, stands out" (p. 483). Although the shortness of the parable format is unlikely to allow for a rich (and 'personalised') mental model of that character, the Samaritan is foregrounded

17 Schneider, Grundriß; Schneider, "Cognitive Theory”; Schneider, “Updated Proposal." 
by his actions deviating from the previous repeated actions of passing the victim by on the other side or the road.

From my perspective, the advantage of using Blending Theory and Cognitive Linguistics in combination lies in the potential for 'zooming' from broad levels of observation (the whole text, such as John, or Luke) via various intermediate entities such as individual passages and dialogues, down to the micro-linguistic level of lexical units that trigger frames; furthermore, the fact that activated frames prime readers for related frames will direct our attention at the dynamic developments of understanding, as Whitenton demonstrates, for instance, with the sympotic dialogues- and the dissembler-frame. Howe and Sweetser present an example of attention to linguistic detail: when the narrator in the Compassionate Samaritan episode remarks that the lawyer follows what he as previously asked Jesus with the question "And who is my neighbour?", he does so in order "to justify himself", as the narrator states, and Howe and Sweetser convincingly argue that "that little phrase alters the purpose (a frame element) of this Conversation" (p. 480). Cognitive and Empirical Literary Studies can learn from cognitive linguistics to pay more attention both to the repercussions of linguistic detail, and to the priming of frames activated dynamically to understand a text.

\subsection{Some Open Questions}

As will have become clear, I fully endorse both the Blending approach and the procedures of Cognitive Linguistics; the readings that Mike Whitenton, Bonnie Howe and Eve Sweetser have produced on the basis of these approaches strike me as extremely convincing. However, from the point of view of Cognitive and Empirical Literary Studies with a focus on readers' reactions to texts, some questions remain to be answered: in that field, it is not predominantly the affordances the text offers, but the question what exactly readers are actually likely - and able - to do in their reading processes. The questions prompted by the two chapters that I will address now should not be understood as problems endemic to the articles or the theoretical approaches they use. Rather, the two contributions give me occasion to address issues that reader-oriented criticism is generally faced with, namely the tensions between predicting potential responses triggered by linguistic cues on the one hand, and assessing to what extent these affordances can in fact be actualised by real readers.

When we reconstruct the input spaces that will be projected into a blend, we ought to keep an eye how many spaces readers can possibly activate, and how the spaces, once activated, are handled in the further dynamics of the reading process. In analysing a potential blend, one must consider what the text directly addresses and then reconstruct the input spaces that are either necessary or 
at least plausibly activated to create emergent meaning. Obviously, through this procedure, we cannot provide 'proof' of which frames and other input spaces are actually activated, but at least reasonable assumptions. Although there seems to be no alternative to such a procedure, the question is whether there are limits to input-space activation at all. The schematic presentations of complex blends, particularly in figures 6 and 7 in Whitenton's article might well be criticised for overstating the load of information that can be processed in the given situation. Whitenton even states that his elaborations are "a simplified representation of the processes that take place as a reader experiences a narrative in real-time and reflects on a character in light of the totality of the story" (p. 529). If this account is simplified, how complex would a full elaboration be? He is certainly right in stating that "no model currently available can predict the intricacies of prior knowledge primed and activated during a narrative simulation" (p. 529). I wonder, however, whether a realistic model would not have to hierarchise the potential processes and to predict which of them are likely to take prominence in actual reading situations, perhaps overruling others that are simply not performed. Similar objections could be raised against the contention, in the chapter by Howe and Sweetser, that "readers place the narrative events and characters in a network of spaces, including the imagined writer Luke, the Jesus who teaches here, and his narrative audience, his disciples" (p. 472; italics mine). The phrasing here implies that even more spaces can be activated (those that provide the spatial and temporal frames, for example), and the chapter goes on to detail the semantic, experiential and cultural frames readers can bring to the reading - but how many more can they plausibly be assumed to activate? Surely the number cannot be unlimited? One solution might be to argue that many of the knowledge structures we have at our disposal in reading are implicit, i.e., we activate them and use them as input spaces automatically, unconsciously, requiring few mental resources and working memory capacities. ${ }^{18}$ Conscious effort will then certainly allow us to 'zoom' into and out of the spaces, and become aware of the connections between them, perhaps only through backward projection after the blend has been established. But do we know how many frames can possibly make up a blend? Can we predict the salience of particular frames really on the basis of textual information only, or might reader variables influence the selection, and if so, to what extent and depending on which factors? Apart from the varying availability of particular knowledge structures between readers, Gibbs and Colston have shown that readers pursue a large variety of goals when reading figurative language, ranging from aiming at quick comprehension via 
a propensity for aesthetic judgment through to emotional reactions. ${ }^{19}$ These overarching aims may also influence frame-activation and blending operations in a given reading situation.

The difficulty of assessing what readers will potentially or actually do in their reading is not specific to Whitenton's approach, but much more general. It comes as no surprise that it is also manifest in the chapter by Howe and Sweetser. Since this issue touches upon some more fundamental considerations about cognitive-emotional response to narrative, the instances deserve a closer look. Howe and Sweetser make a number of claims as to reader's mental operations, judging from the textual evidence. They regard, e.g., the indeterminate description of the man in the parable - "Anthrōpos tis, 'somebody,' 'some person,' 'a man'” - as a cue to gap filling: "This cursory designation forces readers to fill in the profile of that character" (p. 482). Another instance of the kind is the statement that "attentive readers mentally simulate that repeated action" (p. 485), and, referring to Richard Gerrig's concept of transportation to narrative worlds, ${ }^{20}$ "The CL claim is that human embodied cognition primes, enables, and even requires that readers take such journeys." Beside transportation (or related terms such as absorption and immersion), identification plays a major role in many recent studies of narrative engagement (see below). In their analysis of the Compassionate Samaritan parable, Howe and Sweetser state: "If a reader cannot identify with any of the characters, the reading will fail" (p. 489). In all four cases, the potential correlations between textual features and potential reading reactions are plausible enough, but the way they are formulated, they strike me as too strong and exclusive. They also seem to imply an underlying normative attitude towards particular types of reading.

Very generally, no text can coerce any reader into doing anything. As Gerrig points out: "Once we identify a narrative world as some set of processes, we must acknowledge that the experiences of narrative worlds will be optional: a text cannot force a reader to experience a narrative world." ${ }^{21}$ Howe and Sweetser's observation, in the first case mentioned above, that "the flatness of the character allows it to map onto any human being" (p. 482) in my opinion does not automatically lead to the conclusion that it "forces" readers into much gap-filling. It can just as well be taken to argue the opposite view, namely that the indiscriminateness allows the reader not to fill in any details beyond an

19 W.R. Gibbs Jr., H.L. Colston. Interpreting Figurative Meaning (New York: Cambridge University Press, 2012).

20 R.J. Gerrig, Experiencing Narrative Worlds: On the Psychological Activities of Reading (New Haven: Yale University Press, 1993).

21 Gerrig, Experiencing, p. 5 . 
activation of the roughest concept of what 'a man' means to them, or even an awareness only of the function of that item in the story. Also, the exact quality of the contours of that character a reader imagines will depend, not least, on his or her habitual disposition to visualise when reading, and also on the text type. Does the parable really invite that kind of gap-filling, in ways comparable to the novel, as described by Iser? The function of that "somebody" is, after all, to conclude a triad of comparable behaviours (the priest, the Levite, and finally the Samaritan) via incremental repetition, leading to the point of the parable. Since such threefold repetition is found in a variety of popular narrative genres, such as the fairy tale, the joke and the folk ballad, readers may well be satisfied with focusing on the structural function of this 'somebody', without fleshing the character out in their minds. The same question could be asked with regard to the assumption that the repeated action of the parable is in fact mentally simulated: is it actually, in most reader's readings? It seems to me that the relationship between general dispositions and abilities of the human mind and specific genre-dependent affordances requires more investigation.

My critical comments focus on these points because they are connected with what I consider current challenges in the field of cognitive-emotional engagement with narrative in general, as studied by cognitive linguists, cognitive narratologists, and psychologists. As I will elaborate elsewhere, ${ }^{22}$ the investigation of readerly engagement with fictional worlds has been dominated by the study of two phenomena, which in my opinion has overstated some response options and neglected others. Much cognitivist research on literary reading places special emphasis on various types of mental simulation, from classical psychological studies on mental imagery ${ }^{23}$ and the early situation-model approaches to text understanding ${ }^{24}$ via work on emotional simulation ${ }^{25}$ and conceptualisations based on philosophy of mind, ${ }^{26}$ to contributions that consider embodied cognition a crucial factor in literary understanding. ${ }^{27}$ In the last two decades, the general mental, i.e., cognitive and emotional, involvement with literature (mostly narrative fiction) has been studied under the

\footnotetext{
22 Schneider, "Cognitive-Emotional."

23 E.T. Troscianko, "Reading Imaginatively: The Imagination in Cognitive Science and Cognitive Literary Studies", Journal of Literary Semantics 42 (2013), pp. 181-198.

24 Kintsch and van Dijk, Model; Zwaan, Aspects.

25 P.C. Hogan, What Literature Teaches Us About Emotion (Cambridge: Cambridge University Press, 2011); K. Oatley, Such Stuff as Dreams: The Psychology of Fiction (New York: WileyBlackwell, 2011).

26 M. Caracciolo, The Experientiality of Literature: An Enactivist Approach (Berlin and Boston: De Gruyter, 2014).

27 From the sprawling field of embodiment-related theorizing of literary understanding, see, e.g., R.W. Gibbs Jr. and H.L. Colston, "What Psycholinguistic Studies Ignore About Literary Experience," Scientific Study of Literature 9 (2019), pp. 72-103.
} 
labels of 'transportation'28 or 'absorption,"29 sometimes also termed 'immersion. ${ }^{30}$ As far as cognitive-emotional engagement with characters in particular is concerned, the terms 'identification' ${ }^{31}$ and 'empathy'32 have been dominant. Different as these approaches are in terms of their disciplinary, theoretical and methodological affiliations, they all consider the ability to imagine oneself in a fictional world, or even in a particular character's position, a central facet of the reading experience. With the massive recent support of theories on embodied (and embedded, extended, and enactive) cognition ${ }^{33}$ there can be no doubt that humans can mentally project themselves into imagined scenarios; furthermore, the large body of linguistic work on deixis and deictic shifts ${ }^{34}$ as well as viewpoint, ${ }^{35}$ which also relates to work on embodiment, ${ }^{36}$ links that ability to language and its use in narrative. In view of the overwhelming theoretical and empirical evidence just sketched, it seems almost heretical to claim

28 Based on Gerrig, Experiencing, and developed, e.g., by M.C. Green, "Transportation Into Narrative Worlds: The Role of Prior Knowledge and Perceived Realism," Discourse Processes 38 (2004), pp. 247-266; M.C. Green, T.C. Brock, G.F. Kaufman, "Understanding Media Enjoyment: The Role of Transportation into Narrative Worlds," Communication Theory 14 (2004), pp. 311-327.

29 M.M. Kuijpers, F. Hakemulder, E.S. Tan, and M.M. Doicaru, "Exploring Absorbing Reading Experiences," Scientific Study of Literature 4 (2014), pp. 89-122; F. Hakemulder, M.M. Kuijpers, E.S. Tan, K. Bálint, and M.M. Doicaru (eds.), Narrative Absorption (Amsterdam: John Benjamins, 2017).

$30 \quad$ R. Busselle, H. Bilandzic, "Measuring Narrative Engagement," Media Psychology 12 (2009), pp. 321-347.

31 J. Cohen, "Defining Identification: A Theoretical Look at Identification of Audiences with Media Characters," Mass Communication \& Society 4 (2001), pp. 245-264; M. Sestir, M.C. Green, "You Are Who You Watch: Identification and Transportation Effects on Temporary Self-Concept," Social Influence 5 (2010), pp. 272-288; M. Kotovych, P. Dixon, M. Bortolussi, and M. Holden, "Textual Determinants of a Component of Literary Identification," Scientific Study of Literature 1 (2011) 26o-291.

32 S. Keen, Empathy and the Novel (Oxford: Oxford University Press, 2007); A. Coplan, "Empathic Engagement with Narrative Fictions," Journal of Aesthetics and Art Criticism 62 (2014), pp. 141-152.

33 For an introduction to 4 e cognition, see A. Newen, L. de Bruin, and S. Gallagher, " $4 \mathrm{E}$ Cognition: Historical Roots, Key Concepts and Central Issues," in A. Newen, L. de Bruin, and S. Gallagher (eds.), The Oxford Handbook of 4 E Cognition (Oxford: Oxford University Press, 2018), pp. 3-16.

34 See, e.g., J.F. Duchan, G.A. Bruder, and L.E. Hewitt (eds.), Deixis in Narrative: A Cognitive Perspective (Mahwah: Laurence Erlbaum, 1995).

35 L. Vandelanotte, "Viewpoint," in B. Dancygier (ed.), The Cambridge Handbook of Cognitive Linguistics (Cambridge: Cambridge University Press, 2017), pp. 157-171.

$3^{6}$ For an excellent introduction, see E. Sweetser, "Introduction: Viewpoint and Perspective in Language and Gesture from the Ground Down," in B. Dancygier and E. Sweetser (eds.), Viewpoint in Language: A Multimodal Perspective (Cambridge: Cambridge University Press, 2012), pp. 1-22. 
that being fully immersed in a story and adopting the perspective of a character (or, indeed, all of the characters) in the narrative might not be what most readers actually do most of the time. This is precisely what I believe to be the case.

There is enough reason to also consider other possibilities than the immersive and identificatory type of reading. Concepts and terms referring to mental representation and simulation are by no means uncontested in the various research traditions from cognitive linguistics to philosophy of mind, and the concepts listed above are also less clear than one might wish. ${ }^{37}$ As de Graaf and colleagues point out, the different terms and conceptualisations suggest that "the exact nature of the phenomenological experience of reading a narrative is a matter of debate." ${ }^{38}$ The fact that readers' perceived homophily between themselves and a character will influence whether identification occurs ${ }^{39}$ point to the importance of reader variables in the cognitive-emotional engagement with narrative ${ }^{40}$ Furthermore, Laura Otis has shown that readers differ considerably in their willingness and/or ability to actually imagine details when confronted with a scene. ${ }^{41}$ How does that square with the ubiquitous conviction that immersion and empathy, which imply the adoption of a quasi-intrafictional perspective, are standard and even necessary effects of literary reading? In the logic of $\mathrm{CL}$, it is plausible to assume that textual cues will "prime" and "enable" readers to metaphorically go on the journey to the fictional world. However, I would deny that the text "requires" readers to do so.

37 The partial overlap of the terms and the lack of clear distinctions between them, as well as a lack of clarity concerning the mutual indebtedness of the experiences (e.g., how transportation and empathy are related and whether one is a prerequisite for the other) is remarked upon in almost every one of the contributions on these topics quoted above. For an important critical assessment of the transportation metaphor, see M. Bortolussi and P. Dixon, "Transport: Challenges to the Metaphor," in L. Zunshine (ed.), The Oxford Handbook of Cognitive Literary Studies (Oxford: Oxford University Press, 2015), pp. 525-540; for criticism of empathy as a central theoretical concept, see C.J. van Lissa, M. Caracciolo, T. van Duuren, and B. van Leuveren, "Difficult Empathy: The Effect of Narrative Perspective on Readers' Engagement with a First-Person Narrator," DIEGESIS 5 (2016), pp. 43-64.

38 A. de Graaf, H. Hoeken, J. Sanders, and H. Beentjes, "The Role of Dimensions of Narrative Engagement in Narrative Persuasion," Communications 34 (2009), pp. 384-405 (389).

39 Kotovych, Dixon, Bortolussi, and Holden, "Textual Determinants."

40 Cf. also C. Fernandez-Quintanilla, "Textual and Reader Factors in Narrative Empathy: An Empirical Reader Response Study Using Focus Groups," Language and Literature 29 (2020), pp. 124-146.

41 L. Otis, "The Value of Qualitative Research for Cognitive Literary Studies," in L. Zunshine (ed.), The Oxford Handbook of Cognitive Literary Studies (Oxford: Oxford University Press, 2015), pp. 505-524; L. Otis, Rethinking Thought: Inside the Minds of Creative Artists and Scientists (Oxford: Oxford University Press, 2015). 
Also, I would disagree that "if a reader cannot identify with any of the characters, the reading will fail" (p. 489).

I take issue with this for two reasons. First of all, and very generally, I believe that readings can only 'fail' if one has a clear concept of what the 'successful' reading would look like; but that would elevate one interpretation of the text to the status of the only, or best, interpretation. From the point of view of Cognitive and Empirical Literary Studies, the question is not whether a reader successfully arrives at one particular reading, but how texts make some particular sense to particular readers under particular circumstances, at least in a first step. ${ }^{42}$ Second, many studies of transportation and identification create a simplistic dichotomy between immersive reading and an identificatory response to individual characters on the one hand, and an uninvolved, 'mere' spectatorship on the other, as does Jonathan Cohen, for instance: "Unlike the more distanced mode or reception - that of spectatorship - identification is a mechanism through which audience members experience reception an interpretation from the inside, as if the events were happening to them."43 This immersive-identificatory reading is frequently also regarded as the most powerful mode of narrative engagement, because it allegedly has the power to transform the self ${ }^{44}$ - and therefore emerges as the somehow better, preferable, kind of reading.

I do not deny that both immersive and identificatory readings are possible, but I think we need to ask two sets of related questions.

(1) Can we be sure that most readers get transported most of the time and identify or empathise with one character or another in most readings? Are there not many degrees and variants of self-implication that ought to be differentiated? Would a graded scale of cognitive-emotional involvement with a narrative and its characters not do more justice to that variety? There is enough support for such a differentiated approach. Jonathan Cohen, who contributed a widely quoted definition of identification, adds the qualification that identification "is fleeting and varies in intensity [...], a sensation felt intermittently during exposure to a media message". ${ }^{45}$ Oatley and Gholamain refer to Henri Schoenmaker's

42 A second step could then consist in discussing that particular understanding with the reader, and if some authority deems it necessary to impart a different understanding of the text, they will at least know where to start, i.e., they can strategically fill in the frames unavailable to the reader in the first round. This is of course a standard procedure in the literary studies classroom.

43 Cohen, "Defining," p. 245 (italics in the original).

44 Sestir, Green, "You Are"; O. Fialho, "What is Literature For? The Role of Transformative Reading," Cogent Arts \& Humanities 6 (2019), pp. 1-16. 
distinction between the "wish identification" with an idealised other and a "similarity identification" based on the detection of some likeness between the recipient and the character. ${ }^{46}$ Similarly, Kuiken, Miall and Sikora differentiate between the recognition of a "similarity between personal memories and some aspect of the world of the text" and moment in which "the reader becomes identified with some aspect of the world of the text, usually the narrator or character" as two forms of selfimplication in literary reading. ${ }^{47}$ María-Ángeles Martínez has introduced the concept of "storyworld possible selves," combining a possible-worlds theory and a blending approach. ${ }^{48}$ She distinguishes between a) self-schema storyworld possible selves, in which a reader activate self-concepts that have been socially confirmed, b) desired and c) feared storyworld possible selves, in which readers' wish for better, and anxieties of worse, versions of the self respectively come into play, and d) past storyworld possible selves, in which the personal memories and previous self-schemata are involved. I cannot do justice to Martínez' conceptualisation here, but her combination of different types of potential readerly self-implication is extremely promising. ${ }^{49}$ In addition to investigating the considerably different varieties and degrees of immersion and identification further, we also ought to enquire what happens if neither occurs to any notable degree. Surely, such readings cannot be automatically regarded as an impoverished experience that lacks something substantial?

(2) The second set of questions concerns the problem that identification and empathy are mostly understood to relate to one single character. How do readers engage with narrative worlds that have many characters? Most texts used in empirical response studies are (very short) short stories with usually one focal character. For pragmatic reasons, it makes a lot of sense to use such stories for testing, since they allow the researcher to

45 Cohen, "Defining", p. 25 o.

46 K. Oatley and M. Gholamain, "Emotions and Identification," in M. Hjort and S. Laver (eds.), Emotion and the Arts, (New York: Oxford University Press 1997), pp. 263-281 (276-277).

47 D. Kuiken, D. S. Miall, and S. Sikora, "Forms of Self-Implication in Literary Reading," Poetics Today 25 (2004), pp. 171-203 (171).

48 M.-A. Martínez, "Storyworld Possible Selves and the Phenomenon of Narrative Immersion: Testing a New Theoretical Construct," Narrative 22 (2014), pp. 110-131; M.-A. Martínez, StoryWorld Possible Selves (Berlin and New York: Mouton De Gruyter, 2018).

49 For an application of this approach, see J. Alber, "Literature as Identity Laboratory: Storyworld Possible Selves and Boundary Expansions," in A. Nünning and V. Nünning (eds.), The Value of Literature (Tübingen: Narr, 2021), pp. 19-31. 
minimize the number of variables that need to be controlled. However, the vast majority of literary texts are much longer, and they usually feature ensembles of between half a dozen and several dozen characters, and it is not necessarily the case, either, that a multi-character novel has only one protagonist. ${ }^{50}$ How do readers administer their identification/empathy potential to two, three, or more characters? Do they 'jump' from one cognitive-emotional engagement to another? Or is there some kind of dynamic mental network in which not only viewpoints and attitudes of characters are represented, but also the emotional valence attached to them by the reader. One argument against empathic involvement with a single character comes from CL itself. Even for the short parable of the Compassionate Samaritan, Howe and Sweetser observe that "[i]n CL terms, the parable displays multiple distinct viewpoint affordances on the same scene" (p. 484; italics in the original), and Sweester states elsewhere that

We are not just capable of multiple viewpoints; we are in fact incapable of keeping to one single viewpoint of space, or of cognitive structure, when other humans are present. [...] We are constantly aware of our bodily proximity to objects around us, but when another human being is present, we are also unavoidably aware not only of our own bodily affordances, but of (his or) hers as well, what she can reach, what she can see, and so on. ${ }^{51}$

If we assume that readers bring this capacity also to the reading of literature, it becomes implausible to assume the single-character focus is a predominant mode of reception. I would argue that the cognitive-linguistic conception of multiple viewpoints, in combination with other approaches in traditional and cognitive literary scholarship ought to be taken more seriously in modelling response to extended narratives peopled by many characters. ${ }^{52}$ Sonja Zeman has proposed to consider perspectival complexity by distinguishing the reader's awareness of different viewpoints from the necessity of having to share

50 For a lucid exploration of the forms and functions of novels crowded with characters, see A. Woloch, The One vs. the Many: Minor Characters and the Space of the Protagonist in the Novel (Princeton: Princeton University Press, 2003).

$51 \quad$ Sweetser, "Introduction," p. 2 (italics in the original).

$5^{2}$ Literary scholarship has to offer the concepts of polyphony, heteroglossia, and multiperspectivity, all of which emphasize that the point of the (modern) novel is the multiplicity of ideas and worldviews, represented by the many characters, by narrators and focalizers. The concept of multiperspectivity has been considered under the auspices of cognitive approaches; see M. Hartner, "Narrative Theory Meets Blending: Multiperspectivity 
those viewpoints. ${ }^{53}$ Barbara Dancygier and Lieven Vandelanotte use the theory of mental spaces to capture the networks of viewpoints that are partially embedded within each other. ${ }^{54}$ Such approaches would need to be integrated into a theory of cognitive-emotional engagement with character ensembles in extended narratives, combining the insights of both classical and cognitive narratology with models developed by CL and empirical evidence. What the named approaches signal individually is that the reader may inhabit the position of a "monitor", i.e. be neither an uninvolved spectator nor take an intra-fictional position; rather the reader may be mentally placed in between, as an involved observer, as it were.

One last comment concerns the concept of Ground that Howe and Sweetser use. It appears to me to be very broad indeed, and I wonder whether we might perhaps need a more differentiated concept for the distanced communication that characterises literature. Barbara Dancygier's definition of the term Ground, cited by Howe and Sweetser, deserves to be quoted at length here:

I treat the basic communicative context similarly to what cognitive linguists call the Ground [...] - the immediate surroundings, the presence of the speaker and the hearer, shared knowledge, shared visual and aural field, shared understanding of bodily experience, and last but not least, the surrounding discourse context. The Ground makes various aspects of communication possible, since meaning can be derived from ostensive aspects of communication, from objects manifest in the environment, and from the interlocutors' body language, gesture, facial expression, tone of voice, etc. ${ }^{55}$

If these are the constituents of Ground, then it appears that in contrast to interlocutors in face-to-face communication, authors and readers usually share very few of them indeed: if you cut out the italicised items - i.e,. the "ostensive aspects of communication" that are missing in spatially and temporally

Reconsidered," in J. Schlaeger and G. Stedman (eds.), The Literay Mind (REAL: Yearbook of Research in English and American Literature, vol 24; Tübingen: Narr, 2008), pp. 181-193; M. Hartner, "Constructing Literary Character and Perspective: An Approach from Psychology and Blending Theory," in R. Schneider and M. Hartner (eds.), Blending and the Study of Narrative: Approaches and Applications (Berlin and Boston: De Gruyter, 2012), pp. 85-120.

53 S. Zeman, "Confronting Perspectives: Modeling Perspectival Complexity in Language and Cognition," Glossa: A Journal of General Linguistics 2 (2017), pp. 1-22.

54 B. Dancygier and L. Vandelanotte, "Discourse Viewpoint as Network," in B. Dancygier, W. Lu, and A. Verhagen (eds.), Viewpoint and the Fabric of Meaning: Form and Use of Viewpoint Tools across Languages and Modalities (Berlin: De Gruyter, 2016), pp. 13-40.

55 B. Dancygier, The Language of Stories: A Cognitive Approach (Cambridge: Cambridge University Press, 2011), p. 19 (italics added). 
distanced communication - from the quotation above, little remains, only the "shared knowledge" and the "shared understanding of bodily experience." Dancygier argues that particular instances of communication can be replaced by prototypical scenarios:

The difference between the Ground of any specific exchange and the default communicative context is that the latter does not have to profile any individual interlocutors, but rather a generic concept of what engaging in communication is about. Similarly, what is required is a concept of a shared visual field, and not a concrete visual field in a specific exchange. ${ }^{56}$

I wonder which elements readers actually supply from their generic concepts of communicative situations at which point in reading, and whether readers do not also differ considerably in that respect. Such questions, I believe, deserve to be investigated further. I am convinced that many readers actually fill in, mentally, aspects of the potential face-to-face communicative interaction, but which, how many, and influenced by which textual features and reader variables, would be intriguing to find out.

\section{Conclusion: Further Perspectives}

The last comment above demonstrates the fruitfulness of further exchange between exegetes, cognitive and empirical literary scholars, and cognitive linguists. From a reception-oriented point of view, it would be very interesting to establish which frames modern readers actually bring to the reading of, for instance, the Nicodemus passages discussed by Whitenton or the parable of the Compassionate Samaritan analysed by Howe and Sweetser. I would be surprised to learn that previous exposure to narratives in film and other media, for instance, plays no role also in the reception of the Bible. Readers acquire their skills for narrative understanding through exposure to a broad range of multimedia genres, not only written text. The Bible reader does not switch off, as it were, his or her skills of making sense from songs, movies, video clips, Instagram messages, the news, poetry, and literary fiction, etc.

Having said that, it would also be fruitful to further investigate to what extent various modes of Bible reading differ from the reading of modern prose

56 Dancygier, Language, ibid. 
fiction. First, Scripture comprises a variety of types, or genres, of narrative of various length, which may prime certain reading attitudes and frame activations. Second, given the sociocultural embeddedness of Bible reading and exegesis, reading expectations and strategies of meaning-construction are likely to differ from those in leisure-reading, and perhaps more comparable to those we encounter in poetry reading or in discussing literature in the school or university classroom. It is easy to speculate, too, that expert exegetes can and will activate more and other specialised frames than the members of a congregation are likely to do. It may reside in the logic of biblical exegesis to attempt to arrive at a 'correct' reading of a passage of Scripture. From the point of view of Cognitive and Empirical Literary Studies maintaining a strong focus on actual readers' mental operations, however, all understandings of a biblical text make sense - even if they appear nonsensical to the exegete. Our task in this field would be to elicit the conditions under which particular readings come into existence.

All in all, more exchange and dialogue between all disciplines - as exemplified by the present volume - about what readers potentially and actually do in the reading process is called for, because some tacit assumptions and standard procedures may profit from insights from other disciplines. One example may illustrate this: paradoxically, it seems that characters appear more transparent, i.e., psychologically understandable to readers, when the text leaves a number of logical gaps and inconsistencies. ${ }^{57}$ This means that the cognitive-linguistic attention to the presence of linguistic detail in the text must be complemented by the acknowledgement that what is absent from the text will also have considerable effect on readers' cognitive-emotional engagement with at narrative. Even though the field of empirical literary studies is also faced with some challenges, more empirical studies of actual reader's responses to Scripture would be welcome. Having a better understanding of what modern readers do when understanding biblical narrative may provide a touchstone for hypotheses about historical readings, because the intra- and extra-textual factors that shape understanding come into view. Finally, the narratives of the New Testament, as the two articles discussed here have demonstrated, are good starting points for raising some general questions concerning narrative understanding. I have argued that even with single-character narratives or stories with very few characters, there is no necessity to fully immerse or to identify/empathise with one character to have a meaningful and powerful reading

57 Kotovych, Dixon, Bortolussi, and Holden, "Textual Determinants"; M. Caracciolo, "Fictional Characters, Transparency, and Experiential Sharing," Topoi 39 (2020), pp. 811-817. 
experience. This can be read as a challenge to cognitive (and empirical) literary scholarship, cognitive linguistics, and exegesis to develop models for other kinds of reading than the fully immersive and identificatory ones. 